\title{
FAKTOR YANG MEMPENGARUHI DETEKSI KANKER SERVIKS DENGAN METODE TES IVA
}

\author{
Pratiwi Nasution 1 \\ ${ }^{1}$ Fakultas Farmasi dan Kesehatan Prodi Profesi Bidan Institut Kesehatan Helvetia, Medan \\ Email : pratiwinasution@helvetia.ac.id
}

\section{ABSTRACT FACTORS AFFECTING CERVIC CANCER DETECTION USING IVA TEST}

Background; IVA test is a visual inspection with the naked eye all over the surface of the cervix with the help of diluted acetic acid / vinegar. Based on preliminary surveys show that problems that occur women do not want to do IVA examination because many women are shy, lack insight and are afraid to do the examination.

Objectives; to determine the factors that influence early detection of cervical cancer IVA method. Methods; the research design used is Cross Sectional. The population in this study were 142 people with a sample of 59 people. Data collection methods are primary, secondary and tertiary data. Analysis of the data used is univariate, bivariate and multivariate analysis with logistic regression tests.

Results; multivariate analysis sig-p value $0.011<0.05$, sig-p attitude $0.031<0.05$, the role of health cadres sig-p 0.276>0.05, health education sig-p 0.366>0.05, husband support sig-p $0.024<0.05$ and sig-p distance / access $0.014<0.05$.

Conclusion; there is an influence of education, knowledge, attitude, husband support and distance / access to early detection of cervical cancer IVA method, there is no influence of the role of health cadres and health education to early detection of cervical cancer IVA method.

Suggestions For the community, it is hoped that this research can raise awareness for women about the importance of preventing cervical cancer through VIA examinations and provide motivation for women to do cervical cancer screening/early detection so that symptoms of cervical cancer can be recognized as early as possible.

Keywords : Early Detection, Cancer Services, IVA

\section{ABSTRAK}

Latar Belakang Pendahuluan; tes IVA merupakan pemeriksaan inspeksi visual dengan mata telanjang seluruh permukaan leher rahim dengan bantuan asam asetat/cuka yang diencerkan. Berdasarkan survei awal menunjukkan bahwa masalah yang terjadi wanita tidak mau melakukan pemeriksaan IVA dikarenakan banyak wanita yang malu, wawasan yang kurang dan takut melakukan pemeriksaan.

Tujuan; untuk mengetahui faktor yang memengaruhi deteksi dini kanker serviks metode IVA. Metode; desain penelitian yang digunakan adalah Cross Sectional. Populasi dalam penelitian ini sebanyak 142 orang dengan sampel sebanyak 59 orang. Metode pengumpulan data yaitu data primer, sekunder dan tersier. Analisa data yang digunakan yaitu analisis univariat, bivariat dan multivariat dengan uji regresi logistik.

Hasil; analisis multivariat nilai sig-p $0,011<0,05$, sikap sig-p $0,031<0,05$, peran kader kesehatan sig-p $0,276>0,05$, penyuluhan kesehatan sig- $0,366>0,05$, dukungan suami sig- $0,024<0,05$ dan jarak/akses sigp $0,014<0,05$.

Kesimpulan; ada pengaruh pendidikan, pengetahuan, sikap, dukungan suami dan jarak/akses terhadap deteksi dini kanker serviks metode IVA, tidak ada pengaruh peran kader kesehatan dan penyuluhan kesehatan terhadap deteksi dini kanker serviks metode IVA.

Saran Bagi masyarakat diharapkan penelitian ini dapat menumbuhkan kesadaran bagi wanita pentingnya pencegahan terhadap kanker serviks melalui pemeriksaan IVA dan memberikan motivasi bagi wanita untuk melakukan skrinning/deteksi dini kanker serviks sehingga gejala kanker serviks dapat dikenali sedini mungkin.

Kata Kunci : Deteksi Dini, Kanker Serviks, IVA 


\section{JKM (Jurnal Kebidanan Malahayati),Vol 7,No.4.Oktober 2021, ISSN (Print) 2476-8944 ISSN (Online) 2579-762X, Hal 664-672}

\section{PENDAHULUAN}

Angka kejadian kanker di Asia Tenggara adalah yang tertinggi di antara negara-negara di seluruh dunia, dimana Indonesia berada di peringkat teratas bersama Malaysia dan Singapura (WHO 2019). Kanker serviks merupakan penyebab utama kematian wanita akibat kanker di negara berkembang, khususnya Indonesia, yang memiliki prevalensi tertinggi yaitu $0,8 \%$. Setiap tahunnya terdapat sekitar 15.000 kasus baru kanker serviks di Indonesia. Oleh sebab itu, WHO menempatkan Indonesia sebagai negara dengan jumlah penderita kanker serviks terbanyak di dunia . Pada 1.925.943 orang yang melakukan pemeriksaan IVA pada tahun 2007-2016, sebanyak 73.453 orang mendapat hasil positif, dan 1.739 orang dicurigai kanker serviks (Indonesia 2017).

Data dari Dinas Kesehatan Provinsi Sumatera Utara 2018, kasus kanker serviks di Sumatera Utara sebanyak 283 kasus, dengan prevalensi tertinggi pada usia 45-54 tahun. Data dari RSUD dr.Pirngadi Medan jumlah penderita kanker serviks pada tahun 2017 sebanyak 35 kasus, tahun 2016 sebanyak 48 kasus, tahun 2015 sebanyak 40 kasus dan tahun 2014 sebanyak 51 kasus. $80 \%$ dari kasus sudah stadium akhir dan $75 \%$ berakhir dengan kematian (Dinkes Sumut 2019).

Dari profil Dinas Kesehatan Kabupaten Deli Serdang tahun 2017 untuk pemeriksaan kanker leher rahim dengan metode IVA (Inspeksi Visual Asam Asetat) dari 281,229 orang perempuan berusia 30-50 tahun, dilaporkan sebanyak 6.306 yang pernah periksa atau sekitar $2 \%$, namun dari jumlah yang diperiksa di laporkan hanya sekitar 28 orang terdiagnosa IVA positif, pada Tahun 2018 dilaporkan dari 13 Puskesmas yang melakukan pemeriksaan IVA, dengan jumlah wanita yang diperiksa sebanyak 1.7781 orang terdapat 22 orang yang mengalami perubahan warna pada leher rahim setelah melakukan pemeriksaan IVA (IVA Positif) (Dinas Kesehatan Provinsi Sumatera utara 2018).

Perempuan merupakan salah satu elemen penting dalam sebuah keluarga ataupun masyarakat. Karena itu kesehatan perempuan terutama kesehatan reproduksinya menjadi salah satu masalah kesehatan yang penting (Rayburn and Carey 2019) Kesehatan reproduksi adalah keadaan sejarah fisik, mental dan sosial secara utuh, tidak semata-mata bebas dari penyakit atau kecacatan dalam semua hal yang berkaitan dengan sistem reproduksi serta fungsi dan prosesnya (Nugroho 2019) Salah satu organ reproduksi wanita yang rentan terkena penyakit kanker adalah servik dan disebut dengan penyakit kanker servik (Nur and Kep 2017).

Semua jenis penyakit kanker adalah silent killer termasuk kanker serviks, umumnya penyakit ini tidak menunjukkan gejala awal yang bisa dirasakan namun sangat mematikan. Berhubung tidak mengeluhkan gejala apapun, penderita kanker serviks biasanya datang ke rumah sakit ketika penyakitnya sudah mencapai stadium lanjut. Kanker serviks ini dapat muncul pada perempuan usia 35 sampai 55 tahun. Data yang di dapat dari Yayasan Kanker Indonesia tahun 2017 menyebutkan setiap tahunnya sekitar 500.000 perempuan didiagnosa menderita kanker serviks dan lebih dari 250.000 meninggal dunia. Total 2,2 juta perempuan di dunia menderita kanker serviks (Mayanda 2019).

Kanker serviks dapat diantisipasi dengan melakukan deteksi dini. Beberapa deteksi dini yang bisa digunakan untuk mengetahui keberadaan kanker serviks adalah Pap Smear, Pap net, servikografi, tes inspeksi visual asam asetat (IVA), tes high-risk type (HPV), kolposkopi, dan sitologi berbasis cairan (Safitri and Rahmi 2019). Dari beberapa macam metode dalam deteksi dini kanker serviks, tes IVA menjadi metode yang saat ini menjadi program pemerintah di seluruh puskesmas di Indonesia, yaitu dengan gerakan pencegahan dan deteksi dini kanker pada perempuan Indonesia (Cunningham 2019) Kegiatan ini merupakan bagian dalam mewujudkan masyarakat hidup sehat dan berkualitas, hal ini sesuai dengan tercapainya Nawacita kelima yaitu meningkatkan kualitas hidup manusia (Mochtar 2019)

Tes IVA merupakan pemeriksaan inspeksi visual dengan mata telanjang (tanpa pembesaran) seluruh permukaan leher rahim dengan bantuan asam asetat/cuka yang diencerkan. Pemeriksaan IVA hampir sama efektifnya dengan pemeriksaan Pap Smear dalam mendeteksi lesi prakanker (Pieter 2018) Ini merupakan program yang tercantum dalam Keputusan Menteri Kesehatan Republik Indonesia No.796/MENKES/SK/VII/2010 tentang pedoman teknis pengendalian kanker serviks dan payudara (Kemenkes 2017).

Kurangnya kesadaran wanita untuk melakukan deteksi dini kanker serviks mengakibatkan keterlambatan dalam pengobatan akibat penyakit kanker sudah memasuki stadium lanjut. Hasil penelitian Elka (Wigati and Nisak 2017), menunjukkan bahwa terdapat $65 \%$ responden terlambat mencari pengobatan yang disebabkan oleh faktor pengetahuan, akses dan persepsi terhadap penyakit dengan pengaruh sebesar $90 \%$ sedangkan sisanya $10 \%$ dipengaruhi faktor-faktor lain. 
Pemeriksaan IVA merupakan salah satu metode deteksi dini kanker seviks yang aman, murah dan mampu dilaksanakan. Hasil penelitian dari Suryani (Mitchell 2019), bahwa terdapat hubungan pengetahuan WUS dengan pemeriksaan IVA, terdapat hubungan sikap WUS dengan pemeriksaan IVA, Terdapat hubungan antara pengetahuan dan sikap WUS dengan pemeriksaan IVA di Puskesmas Buleleng I, Kecamatan Buleleng.

Hasil penelitian Rismawari didapatkan ada hubungan bermakna terhadap keikutsertaan ibu dalam tes IVA yaitu pengetahuan, biaya, ketersediaan informasi, dukungan suami dan dukungan petugas kesehatan(Marhaeni A 2016). Sejalan dengan pendapat Notoatmodjo (Notoadmodjo 2016) yang mengutip pendapat (Sastrawinata, Martaadisoebrata, and Wirakusumah 2017) dapat disimpulkan bahwa aspek sosial budaya dapat mempengaruhi perilaku kesehatan.

Berdasarkan survey awal yang telah dilakukan peneliti pada tanggal 12 Maret 2019 sampai tanggal 18 Maret 2019 di puskesmas Kenangan Kecamatan Percut Sei Tuan Kabupaten Deli Serdang tanggal 18-23 Maret 2019 dari total populasi 17.133 wanita yang sudah menikah yang berkunjung di puskesmas Kenangan diambil 100 sampel secara acak dengan tingkat presisi sebesar $10 \%$ kemudian peneliti mewawancarai ibu-ibu tersebut, yang menyatakan takut akan hasil setelah melakukan pemeriksaan IVA sebanyak 20 orang, tidak melakukan pemeriksaan IVA karena malu, karena tabu alat kelamin dilihat orang sebanyak 29 orang, menyatakan tidak tahu informasi tentang pemeriksaan IVA sebanyak 20 orang, 10 orang menyatakan bahwa jarak lokasi pemeriksaan jauh dari rumah mereka serta kurangnya dukungan dari suami sebanyak 21 orang. Pelaksanaan IVA di puskesmas Kenangan dilakukan setiap hari Senin sampai Rabu dengan jumlah tenaga medis yang terlatih tiga orang yang terdiri dari dua orang bidan dan satu orang dokter.

Berdasarkan latar belakang, maka peneliti tertarik untuk melakukan penelitian tentang faktor yang memengaruhi deteksi dini kanker serviks metode IVA di Puskesmas Kenangan Kabupaten Deli Serdang tahun 2019. Tujuan penelitian ini yaitu untuk mengetahui faktor yang memengaruhi deteksi dini kanker serviks metode IVA di Puskesmas Kenangan Kabupaten Deli Serdang tahun 2019.

\section{METODE PENELITIAN}

Desain penelitian yang digunakan dengan survei analitik. Pada penelitian ini menggunakan pendekatan cross sectional Lokasi dalam penelitian ini dilakukan di puskesmas Kenangan kecamatan
Percut Sei Tuan Kabupaten Deli Serdang tahun 2019 dan waktu penelitian ini dimulai dari bulan Februari sampai Agustus 2019. Tahapan dilaksanakan mulai dari pengambilan data yang diperoleh secara langsung dari responden melalui kuesioner kemudian memeriksa kelengkapan jawaban kuesioner atau lembar observasi dengan tujuan agar data diolah secara benar sehingga pengolahan data memberikan hasil yang valid dan reliabel dan terhindar dari bias setah itu Semua data diinput kedalam aplikasi komputer akan diolah sesuai dengan kebutuhan. Populasi dalam penelitian ini adalah seluruh wanita sudah menikah yang berusia 30-50 tahun yang berada di wilayah Puskesmas Kenangan Kecamatan Percut Sei Tuan Kabupaten Deli Serdang sebanyak 142 orang. Pengambilan sampel menggunakan metode accidental sampling dengan jumlah 59 orang. Analisis data yang digunakan yaitu analisis deskriptif dan bivariat. Analisis data secara univariat dilakukan untuk menggambarkan karakteristik masing-masing variabel independen dan variabel dependen. Analisis bivariat dilakukan untuk membuktikan ada tidak hubungan yang signifikan antara variabel bebas dengan variabel terikat dengan menggunakan uji Chi-square. Analisis data multivariat dilakukan dengan uji regresi logistik, yang bertujuan untuk mengetahui adanya pengaruh variabel-variabel bebas terhadap variabel terikat.

\section{HASIL DAN PEMBAHASAN}

Tabel 1.

Distribusi Frekuensi Responden Berdasarkan

Pendidikan, Pengetahuan, Sikap, Peran Kader Kesehatan, Penyuluhan Kesehatan di

Puskesmas Kenangan Kabupaten Deli Serdang tahun 2019

\begin{tabular}{lcc}
\hline \multirow{2}{*}{\multicolumn{1}{c}{ Variabel }} & \multicolumn{2}{c}{ Jumlah } \\
\cline { 2 - 3 } & N & $\%$ \\
\hline Pendidikan & 25 & 42,2 \\
Tinggi & 34 & 57,6 \\
Rendah & & \\
Pengetahuan & 31 & 52,5 \\
Tidak Baik & 28 & 47,5 \\
Baik & & \\
Sikap & 32 & 54,2 \\
Negatif & 27 & 45,8 \\
Positif & & \\
Peran Kader Kesehatan & 34 & 57,6 \\
Tidak Baik & 25 & 42,4 \\
Baik & & \\
Penyuluhan Kesehatan & 26 & 44,1 \\
Rendah & 33 & 55,9 \\
Tinggi &
\end{tabular}


Berdasarkan Tabel 1. Hasil yang didapat dari 59 responden dapat disimpulakan bahwa yang mayoritas memiliki pendidikan tinggi (SMA, diploma dan sarjana) yaitu sebanyak 25 responden $(42,2 \%)$, mayoritas sebanyak 31 responden (52,5\%) memiliki pengetahuan tidak baik, mayoritas sebanyak 32 responden $(54,2 \%)$ memiliki sikap yang negatif, mayoritas sebanyak 34 responden $(57,6 \%)$ menyatakan peran kader kesehatan tidak baik dan mayoritas sebanyak 26 responden $(44,1 \%)$ menyatakan penyuluhan kesehatan rendah.

Berdasarkan tabel 2 dari 59 responden, mayoritas sebanyak 34 responden $(57,6 \%)$ tidak mendapatkan dukungan dari suami, mayoritas 33 responden $(55,9 \%)$ menyatakan jarak/akses tidak terjangkau, mayoritas sebanyak 26 responden $(44,1 \%)$ menyatakan jarak/akses terjangkau dan sebanyak 37 responden $(62,7 \%)$ yang tidak melakukan pemeriksaan IVA.
Tabel 2.

Distribusi Frekuensi Responden Berdasarkan SDukungan Suami, Jarak/Akses dan deteksi dini kanker serviks metode IVA di Puskesmas Kenangan Kabupaten Deli Serdang tahun 2019

\begin{tabular}{lcc}
\hline \multirow{2}{*}{ Variabel } & \multicolumn{2}{c}{ Jumlah } \\
\cline { 2 - 3 } & $\mathbf{n}$ & $\%$ \\
\hline Dukungan Suami & & 57,6 \\
TidakMendukung & 34 & 42,4 \\
Mendukung & 25 & \\
Jarak/Akses & & 55,9 \\
Tidak Terjangkau & 33 & 44,1 \\
Terjangkau & 26 & \\
Pemeriksaan IVA & & 62,7 \\
Tidak Melakukan & 37 & 37,3 \\
Melakukan & 22 & \\
\hline
\end{tabular}

Tabel 3.

Tabulasi Silang antara Pendidikan, Pengetahuan, Sikap, Peran Kader Kesehatan, Penyuluhan Kesehatan, Dukungan Suami, Jarak/Akses dengan deteksi dini kanker serviks Metode IVA di Puskesmas Kenangan Kabupaten Deli Serdang tahun 2019

\begin{tabular}{|c|c|c|c|c|c|c|c|}
\hline \multirow{3}{*}{ Variabel } & \multicolumn{4}{|c|}{ Pemeriksaan IVA } & \multirow{2}{*}{\multicolumn{2}{|c|}{ Total }} & \multirow{3}{*}{ Sig-p } \\
\hline & \multicolumn{2}{|c|}{ Tidak Melakukan } & \multicolumn{2}{|c|}{ Melakukan } & & & \\
\hline & $\mathrm{n}$ & $\%$ & $\mathrm{n}$ & $\%$ & $\mathbf{N}$ & $\%$ & \\
\hline \multicolumn{8}{|l|}{ Pendidikan } \\
\hline Rendah & 27 & 45,8 & 7 & 11,9 & 34 & 57,6 & 0,005 \\
\hline Tinggi & 10 & 16,9 & 15 & 25,4 & 25 & 42,4 & \\
\hline \multicolumn{8}{|l|}{ Pengetahuan } \\
\hline Tidak Baik & 25 & 42,4 & 6 & 10,2 & 31 & 52,5 & 0,006 \\
\hline Baik & 12 & 20,3 & 16 & 27,1 & 28 & 47,5 & \\
\hline \multicolumn{8}{|l|}{ Sikap } \\
\hline Negatif & 17 & 28,8 & 15 & 25,4 & 32 & 54,2 & 0,165 \\
\hline Positif & 20 & 33,9 & 7 & 11,9 & 27 & 45,8 & \\
\hline \multicolumn{8}{|c|}{ Peran Kader Kesehatan } \\
\hline Tidak Baik & 23 & 39,0 & 11 & 18,6 & 34 & 57,6 & 0,521 \\
\hline Baik & 14 & 23,7 & 11 & 18,6 & 25 & 42,4 & \\
\hline \multicolumn{8}{|c|}{ Penyuluhan Kesehatan } \\
\hline Rendah & 17 & 28,8 & 9 & 15,3 & 26 & 44,1 & 0,916 \\
\hline Tingqi & 20 & 33,9 & 13 & 22,0 & 33 & 55,9 & \\
\hline \multicolumn{8}{|l|}{ Dukungan Suami } \\
\hline Tidak Mendukung & 19 & 32,2 & 15 & 25,4 & 34 & 57,6 & 0,321 \\
\hline $\begin{array}{l}\text { Medukung } \\
\text { Jarak/Akses }\end{array}$ & 18 & 30,5 & 7 & 11,9 & 25 & 42,4 & \\
\hline Tidak Terjangkau & 25 & 42,4 & 8 & 13,6 & 33 & 55,9 & 0,039 \\
\hline Terjangkau & 12 & 20,3 & 14 & 23,7 & 26 & 44,1 & \\
\hline
\end{tabular}

Berdasarkan tabel 3 tabulasi silang antara pendidikan dengan pemeriksaan IVA, diketahui bahwa 34 responden $(57,6 \%)$ memiliki pendidikan rendah didapatkan sebanyak 27 responden $(45,8 \%)$ tidak melakukan pemeriksaan IVA. Selanjutnya dari
25 responden $(42,4 \%)$ memiliki pendidikan tinggi didapatkan sebanyak 15 responden $(25,4 \%)$ melakukan pemeriksaan IVA. Berdasarkan hasil uji chi-square dapat dilihat sig-p $=0,005(<0,05)$ artinya bahwa pendidikan memiliki pengaruh 
dengan deteksi dini kanker serviks metode IVA di Puskesmas Kenangan Kecamatan Percut Sei Tuan Kabupaten Deli Serdang tahun 2019.

Berdasarkan tabel tabulasi silang antara pengetahuan dengan pemeriksaan IVA, diketahui bahwa 31 responden (52,5\%) memiliki pengetahuan tidak baik didapatkan sebanyak 25 responden $(42,4 \%)$ tidak melakukan pemeriksaan IVA. Selanjutnya dari 28 responden $(47,5 \%)$ memiliki pengetahuan baik didapatkan 16 responden $(27,1 \%)$ melakukan pemeriksaan IVA. Berdasarkan hasil uji chi-square dapat dilihat sig-p $=0,006(<$ $0,05)$ artinya bahwa pengetahuan memiliki pengaruh dengan deteksi dini kanker serviks metode IVA di Puskesmas Kenangan Kecamatan Percut Sei Tuan Kabupaten Deli Serdang tahun 2019.

Berdasarkan tabel tabulasi silang antara sikap dengan pemeriksaan IVA, diketahui bahwa 32 responden $(54,2 \%)$ memiliki sikap negatif didapatkan sebanyak 17 responden $(28,8 \%)$ tidak melakukan pemeriksaan IVA. Selanjutnya dari 27 responden $(45,8 \%)$ memiliki sikap positif didapatkan sebanyak 20 responden $(33,9 \%)$ tidak melakukan pemeriksaan IVA. Berdasarkan hasil uji chi-square dapat dilihat sig-p $=0,165(>0,05)$ artinya bahwa sikap tidak memiliki pengaruh dengan deteksi dini kanker serviks metode IVA di Puskesmas Kenangan Kecamatan Percut Sei Tuan Kabupaten Deli Serdang tahun 2019.

Berdasarkan tabel tabulasi silang antara peran kader kesehatan dengan pemeriksaan IVA, diketahui bahwa 34 responden $(57,6 \%)$ menyatakan peran kader kesehatan tidak baik didapatkan sebanyak 23 responden $(39,0 \%)$ tidak melakukan pemeriksaan IVA. Selanjutnya dari 25 responden $(42,4 \%)$ menyatakan peran kader kesehatan baik didapatkan sebanyak 14 responden $(23,7 \%)$ tidak melakukan pemeriksaan IVA Berdasarkan hasil uji chi-square dapat dilihat sig-p $=0,521(>0,05)$ artinya bahwa peran kader kesehatan tidak memiliki pengaruh dengan Deteksi Dini Kanker Serviks Metode IVA di Puskesmas Kenangan Kecamatan Percut Sei Tuan Kabupaten Deli Serdang tahun 2019.

Berdasarkan tabel tabulasi silang antara penyuluhan kesehatan dengan pemeriksaan IVA, diketahui bahwa 26 responden $(44,1 \%)$ menyatakan penyluhan kesehatan rendah didapatkan sebanyak 17 responden $(28,8 \%)$ tidak melakukan pemeriksaan IVA. Selanjutnya dari 33 responden $(55,9 \%)$ menyatakan penyuluhan kesehatan tinggi didapatkan sebanyak 20 responden (33,9\%) tidak melakukan pemeriksaan IVA. Berdasarkan hasil uji chi-square dapat dilihat sig-p $=0,916(>0,05)$ artinya bahwa penyuluhan kesehatan tidak memiliki pengaruh dengan deteksi dini kanker serviks metode IVA di Puskesmas Kenangan Kecamatan Percut Sei Tuan Kabupaten Deli Serdang tahun 2019.

Berdasarkan tabel tabulasi silang antara dukungan suami dengan pemeriksaan IVA, diketahui bahwa 34 responden (57,6\%) memiliki suami yang tidak mendukung didapatkan sebanyak 19 responden (32,2\%) tidak melakukan pemeriksaan IVA. Selanjutnya dari 25 responden $(42,4 \%)$ memiliki suami yang mendukung didapatkan sebanyak 18 responden (30,5\%) tidak melakukan pemeriksaan IVA. Berdasarkan hasil uji chi-square dapat dilihat sig-p $=0,321(>0,05)$ artinya bahwa dukungan suami tidak memiliki pengaruh dengan deteksi dini kanker serviks metode IVA di Puskesmas Kenangan Kecamatan Percut Sei Tuan Kabupaten Deli Serdang tahun 2019.

Berdasarkan tabel tabulasi silang antara jarak/akses dengan pemeriksaan IVA, diketahui bahwa 33 responden $(55,9 \%)$ menyatakan jarak/akses tidak terjangkau didapatkan sebanyak 25 responden (42,4\%) tidak melakukan pemeriksaan IVA. Selanjutnya dari 26 responden $(44,1 \%)$ menyatakan jarak/akses terjangkau didapatkan sebanyak 12 responden $(20,3 \%)$ tidak melakukan pemeriksaan IVA. Berdasarkan hasil uji chi-square dapat dilihat sig-p $=0,039(<0,05)$ artinya bahwa jaraklakses memiliki pengaruh dengan deteksi dini kanker serviks metode IVA di Puskesmas Kenangan Kecamatan Percut Sei Tuan Kabupaten Deli Serdang tahun 2019

Tabel 4.

Hasil Uji Multivariat Regresi Logistik

\begin{tabular}{lccc}
\hline \multicolumn{1}{c}{ Variabel } & B & Sig. & Exp(B) \\
\hline Pendidikan & 1,563 & 0,041 & 4,774 \\
Pengetahuan & 1,981 & 0,011 & 7,248 \\
Sikap & $-1,808$ & 0,031 & 0,164 \\
Dukungan_Suami & $-1,940$ & 0,024 & 0,144 \\
Jarak & 2,161 & 0,014 & 8,681 \\
Constant & $-1,820$ & 0,013 & 0,162 \\
\hline
\end{tabular}

Berdasarkan tabel 4 hasil uji yang dilakukan pada penelitian ini menggunakan $a=0,05$, variabel bebas (independen) yang mempunyai pengaruh secara signifikan dengan variabel terikat (dependen) adalah sebagai berikut :

Pendidikan memiliki nilai sig-p $0,041<0,05$ artinya pendidikan memiliki pengaruh secara 


\section{JKM (Jurnal Kebidanan Malahayati),Vol 7,No.4.Oktober 2021, ISSN (Print) 2476-8944 ISSN (Online) 2579-762X, Hal 664-672}

signifikan terhadap deteksi dini kanker serviks metode IVA di Puskesmas Kenangan Kecamatan Percut Sei Tuan Kabupaten Deli Serdang tahun 2019. Pengetahuan memiliki nilai sig-p $0,011<0,05$ artinya pengetahuan memiliki pengaruh secara signifikan terhadap deteksi dini kanker serviks metode IVA di Puskesmas Kenangan Kecamatan Percut Sei Tuan Kabupaten Deli Serdang tahun 2019. Sikap memiliki nilai sig-p $0,031<0,05$ artinya sikap memiliki pengaruh secara signifikan terhadap deteksi dini kanker serviks metode IVA di Puskesmas Kenangan Kecamatan Percut Sei Tuan Kabupaten Deli Serdang tahun 2019. Dukungan Suami memiliki nilai sig-p 0,024 $<0,05$ artinya dukungan suami memiliki pengaruh secara signifikan terhadap deteksi dini kanker serviks metode IVA di Puskesmas Kenangan Kecamatan Percut Sei Tuan Kabupaten Deli Serdang tahun 2019. Jarak/akses memiliki nilai sig-p 0,014 < 0,05 artinya jarak/akses memiliki pengaruh secara signifikan terhadap deteksi dini kanker serviks metode IVA di Puskesmas Kenangan Kecamatan Percut Sei Tuan Kabupaten Deli Serdang tahun 2019.

\section{PEMBAHASAN}

Pengaruh Pendidikan terhadap Deteksi Dini Kanker Serviks Metode IVA di Puskesmas Kenangan : berdasarkan tabel tabulasi silang antara pendidikan dengan pemeriksaan IVA, diketahui bahwa 34 responden $(57,6 \%)$ memiliki pendidikan rendah didapatkan sebanyak 27 responden $(45,8 \%)$ tidak melakukan pemeriksaan IVA. Selanjutnya dari 25 responden $(42,4 \%)$ memiliki pendidikan tinggi didapatkan 15 responden (25,4\%) melakukan pemeriksaan IVA. Hasil analisis uji regresi logistic menunjukkan bahwa pendidikan memiliki nilai sig-p $0,045<0,05$ artinya pendidikan memiliki nilai sig-p $0,041<0,05$ artinya pendidikan memiliki pengaruh secara signifikan terhadap deteksi dini kanker serviks metode IVA di Puskesmas Kenangan Kecamatan Percut Sei Tuan Kabupaten Deli Serdang tahun 2019.

Sejalan dengan penelitian yang dilakukan oleh Ikrima tahun 2019 tentang Pengaruh Pendidikan Kesehatan Deteksi Dini Kanker Serviks dengan Metode IVA Terhadap Motivasi lbu di Kelurahan Mojosongo RW XIV Surakarta, menunjukkan bahwa sebelum dan sesudah pemberian pendidikan kesehatan pada kelompok perlakuan mayoritas responden mempunyai motivasi sedang, pada hasil pretest dan posttest kelompok kontrol mayoritas responden mempunyai motivasi sedang. Hasil penelitian didapatkan Zhitung -3.606 dan $p$-value sebesar 0.000 .
Kesimpulan penelitian ini terdapat pengaruh pemberian pendidikan kesehatan deteksi dini kanker serviks dengan metode IVA di Kelurahan Mojosongo RW XIV Surakarta (Ikrima 2015).

Menurut asumsi penelitian menunjukkan perbedaan tersebut diatas kemungkinan berpengaruh pengetahuan dan pendidikan kesehatan yang didapatkan wanita yang melakukan pemeriksaan IVA, kemungkinan bisa karena ikutikutan teman/saudara, dan karena disuruh orang yang berpengaruh, tanpa tahu tujuan dan manfaatnya. Meningkatnya pendidikan seseorang akan membuat orang tersebut semakin peduli terhadap kesehatannya. Pendidikan yang dijalani seseorang memiliki pengaruh pada peningkatan kemampuan berfikir, dimana seseorang yang berpendidikan lebih tinggi akan dapat mengambil keputusan yang lebih rasional, umumnya terbuka untuk menerima perubahan atau hal baru dibandingkan dengan individu yang berpendidikan lebih rendah (Sayuti and Nouva 2019).

Pengaruh Pengetahuan terhadap Deteksi Dini Kanker Serviks Metode IVA di Puskesmas Kenangan : berdasarkan tabel tabulasi silang antara pengetahuan dengan pemeriksaan IVA, diketahui bahwa 31 responden $(52,5 \%)$ memiliki pengetahuan tidak baik didapatkan sebanyak 25 responden $(42,4 \%)$ tidak melakukan pemeriksaan. Selanjutnya dari 28 responden $(47,5 \%)$ memiliki pengetahuan baik didapatkan 16 responden $(27,1 \%)$ melakukan pemeriksaan IVA. Hasil analisis uji regresi logistic menunjukkan bahwa pengetahuan memiliki nilai sigp $0,011<0,05$ artinya pengetahuan memiliki pengaruh secara signifikan terhadap deteksi dini kanker serviks metode IVA di Puskesmas Kenangan Kecamatan Percut Sei Tuan Kabupaten Deli Serdang tahun 2019.

Sejalan dengan penelitian yang dilakukan oleh Utami tahun 2013 tentang Hubungan Tingkat Pengetahuan Pasangan Usia Subur Dengan Perilaku Deteksi Dini Kanker Serviks di Wilayah Kerja Puskesmas Sangkrah Kecamatan Pasar Kliwon Surakarta, menunjukkan bahwa pengetahuan ibu terhadap deteksi dini kanker serviks sebagian besar adalah tinggi (72\%), perilaku deteksi dini kanker serviks sebagian besar adalah tidak melakukan deteksi dini $(68 \%)$ dan terdapat hubungan yang signifikan antara pengetahuan tentang deteksi dini kanker serviks dengan perilaku deteksi dini kanker serviks pada pasangan usia subur di wilayah kerja Puskesmas Sangkrah Kecamatan Pasar Kliwon Surakarta ( $p$ value $=0,017)$ (Utami 2013).

Menurut asumsi peneliti dalam upaya peningkatan tingkat pengetahuan perlu dilakukan 
penyuluhan rutin mengenai kanker serviks dan deteksi dini kanker serviks metode IVA agar masyarakat luas lebih mengenal dengan baik mengenai kanker serviks dan deteksi dini kanker serviks metode IVA. Pengetahuan dikatakan sebagai alat yang dapat digunakan untuk memecahkan masalah yang dihadapi manusia. Sehingga melalui pengetahuan yang didapat, orang akan mencari alat untuk memecahkan masalahnya, dan terkait dengan kanker leher rahim maka orang akan mencari tahu tentang penyebab, cara penularan, pencegahan, maupun cara mendeteksinya, sehingga selanjutnya akan melakukan pemeriksaan IVA secara rutin dan tepat waktu, sebagai bentuk pemecahan masalah tersebut (Putri 2018).

Pengaruh Sikap terhadap Deteksi Dini Kanker Serviks Metode IVA di Puskesmas Kenangan : berdasarkan tabel tabulasi silang antara sikap dengan pemeriksaan IVA, diketahui bahwa 32 responden $(54,2 \%)$ memiliki sikap negatif didapatkan sebanyak 17 responden (28,8\%) tidak melakukan pemeriksaan IVA. Selanjutnya dari 27 responden $(45,8 \%)$ memiliki sikap positif didapatkan sebanyak 20 responden $(33,9 \%)$ tidak melakukan pemeriksaan IVA. Hasil analisis uji regresi logistic menunjukkan bahwa sikap memiliki nilai sig-p 0,031 $<0,05$ artinya sikap memiliki pengaruh secara signifikan terhadap deteksi dini kanker serviks metode IVA di Puskesmas Kenangan Kecamatan Percut Sei Tuan Kabupaten Deli Serdang tahun 2019.

Sejalan dengan penelitian yang dilakukan oleh Diasih tahun 2017 tentang Faktor-Faktor yang Berhubungan dengan Upaya Wanita Usia Subur Melakukan Deteksi Dini Kanker Serviks, menunjukkan bahwa pada variabel sikap didapatkan hasil uji stastistik dimana $p$ value $=$ $0,000(p<0,05)$ yang menunjukan adanya hubungan yang signifikan antara sikap dengan upaya WUS melakukan deteksi dini kanker serviks (Diasih 2017).

Menurut asumsi peneliti suatu sikap belum otomatis terwujud dalam bentuk praktek. Untuk terwujudnya sikap agar menjadi suatu perbuatan yang nyata (praktik) diperlukan faktor pendukung atau kondisi yang memungkinkan. Sikap sangat menentukan seseorang ke arah lebih baik. Upaya yang dapat dilakukan untuk membentuk sikap tersebut dapat diwujudkan melalui pemberdayaan tenaga kesehatan untuk memberikan pemahaman tentang pentingnya deteksi dini kanker serviks melalui metode IVA kepada masyarakat secara berkala. Sikap positif akan memunculkan perilaku wanita pasangan usia subur (PUS) yang baik untuk melakukan deteksi dini kanker serviks melalui metode IVA. Sebenarnya ada sebahagian masyarakat dalam hal ini wanita pasangan usia subur yang sudah tahu tentang deteksi dini kanker serviks, tetapi mereka belum melakukan tindakan deteksi dini tersebut (Mardiah 2019).

Pengaruh Dukungan Suami terhadap Deteksi Dini Kanker Serviks Metode IVA di Puskesmas Kenangan : berdasarkan tabel tabulasi silang antara dukungan suami dengan pemeriksaan IVA, diketahui bahwa 34 responden (57,6\%) memiliki suami yang tidak mendukung didapatkan sebanyak 19 responden (32,2\%). Selanjutnya dari 25 responden $(42,4 \%)$ memiliki suami yang mendukung didapatkan sebanyak 18 responden $(30,5 \%)$. Hasil analisis uji regresi logistic menunjukkan bahwa dukungan suami memiliki nilai sig-p $0,024<0,05$ artinya dukungan suami memiliki pengaruh secara signifikan terhadap deteksi dini kanker serviks metode IVA di Puskesmas Kenangan Kecamatan Percut Sei Tuan Kabupaten Deli Serdang tahun 2019.

Sejalan dengan penelitian yang dilakukan oleh Wijayanti tahun 2015 tentang Hubungan Dukungan Suami dengan Keikutsertaan IVA pada Wanita Usia Subur di Puskesmas Sedayu I dan Puskesmas Sedayu II, menunjukkan bahwa ada hubungan dukungan suami dengan keikutsertaan IVA pada wanita usia subur (WUS) dengan tingkat keeratan yang kuat di Puskesmas Sedayu I dan Puskesmas Sedayu II Bantul. Dibuktikan dengan hasil uji chi-square diperoleh nilai X2 hitung sebesar 76.119; taraf signifikan 0.000 (pvalue $<0,05$ ); dan koefisien kontigensi sebesar $0.654(0,60-0,799)$ (Wijayanti 2015).

Menurut asumsi peneliti dukungan dapat berupa motivasi dan ikut mengingatkan wanita tentang pentingnya deteksi dini kanker serviks, namun pada kenyataannya dukungan suami/keluarga yang diberikan belumlah optimal sehingga wanita kurang termotivasi untuk melakukan tindakan deteksi dini kanker serviks. Hal ini disebabkan masih kurangnya pengetahuan yang dimiliki oleh suami/keluarga tersebut (Husnah 2021). Partisipasi anggota keluarga terutama keluarga terdekat seperti suami/mertua menjadi hal yang penting untuk diperhatikan dalam efektivitas dukungan yang diterimanya, anggapan bahwa dukungan dapat tersedia ketika dibutuhkan menjadi hal yang penting dan berkaitan dengan kesehatan dan penyesuaian diri pada seseorang. Mengetahui bahwa suami/keluarga bersedia untuk menyediakan bantuan, kenyamanan, dan rasa tertarik mungkin dapat membantu wanita untuk termotivasi 


\section{JKM (Jurnal Kebidanan Malahayati),Vol 7,No.4.Oktober 2021, \\ ISSN (Print) 2476-8944 ISSN (Online) 2579-762X, Hal 664-672}

melakukan deteksi dini kanker serviks melalui metode IVA (Agustina 2019)

Pengaruh Jarak/Akses terhadap Deteksi Dini Kanker Serviks Metode IVA di Puskesmas Kenangan : berdasarkan tabel tabulasi silang antara jarak/akses dengan pemeriksaan IVA, diketahui bahwa 33 responden (55,9\%) menyatakan jarak/akses tidak terjangkau didapatkan sebanyak 25 responden (42,4\%). Selanjutnya dari 26 responden $(44,1 \%)$ menyatakan jarak/akses terjangkau didapatkan 14 responden $(23,7 \%)$ melakukan pemeriksaan IVA. Hasil analisis uji regresi logistic menunjukkan bahwa jarak/akses memiliki nilai sig-p 0,014<0,05 artinya jarak/akses memiliki pengaruh secara signifikan terhadap deteksi dini kanker serviks metode IVA di Puskesmas Kenangan Kecamatan Percut Sei Tuan Kabupaten Deli Serdang tahun 2019.

Menurut penelitian yang dilakukan oleh Yuliwati tahun 2012 tentang Faktor-Faktor yang Berhubungan dengan Perilaku WUS dalam Deteksi Dini Kanker Leher Rahim Metode IVA di Wilayah Puskesmas Prembun Kabupaten Kebumen, menunjukkan bahwa terdapat hubungan yang signifikan antara keterjangkauan jarak/tempat layanan dengan pemeriksaan IVA, dengan $p$ value 0,003 (Yuliwati 2012).

Menurut asumsi peneliti jarak fasilitas kesehatan yang memberikan pelayanan pemeriksaan IVA yang terjangkau bagi wanita akan meningkatkan perilaku pemeriksaan IVA. Karena jarak membatasi kemampuan dan kemauan wanita untuk mencari pelayanan, terutama jika sarana transportasi yang tersedia terbatas, komunikasi sulit dan di daerah tersebut tidak tersedia tempat layanan. Jarak merupakan rentang yang harus ditempuh seseorang dari suatu tempat ke tempat yang dituju. Jarak sangat mempengaruhi seseorang untuk melakukan tindakan kesehatan (Ardhiansyah 2019) Semakin dekat jarak maka semakin mendukung seseorang untuk bisa melakukan kunjungan ke pelayanan kesehatan dan sebaliknya, semakin jauh jarak semakin menjadi hambatan bagi sesorang untuk melakukan kunjungan ke pelayanan kesehatan (Darmareja et al. 2021) Dalam upaya penjangkauan WUS di berbagai bagian wilayah perlu dilakukan peningkatan koordinasi antara puskesmas wilayah dengan puskesmas pembantu atau kader kesehatan.

\section{SIMPULAN}

Kesimpulan dalam penelitian ini adalah ada pengaruh pendidikan, pengetahuan, sikap, dukungan suami dan jarak/akses terhadap deteksi dini kanker serviks metode IVA, sedangkan peran tenaga kesehatan dan penyuluhan kesehatan tidak memiliki pengaruh terhadap deteksi dini kanker serviks metode IVA di Puskesmas Kenangan Kecamatan Percut Sei Tuan Kabupaten Deli Serdang tahun 2019.

\section{SARAN}

Bagi masyarakat diharapkan penelitian ini dapat menumbuhkan kesadaran bagi wanita pentingnya pencegahan terhadap kanker serviks melalui pemeriksaan IVA dan memberikan motivasi bagi wanita untuk melakukan skrinning/deteksi dini kanker serviks sehingga gejala kanker serviks dapat dikenali sedini mungkin.

\section{DAFTAR PUSTAKA}

Agustina, Santi. 2019. "Penyuluhan Kanker Serviks Dan Pemeriksaan Kesehatan Melalui Tes Iva Di Cipayung Jakarta Timur." Jurnal Pelayanan Dan Pengabdian Masyarakat (Pamas) 3(1):49-52.

Ardhiansyah, Azril Okta. 2019. Deteksi Dini Kanker. Vol. 1. Airlangga University Press.

Cunningham, F.Gary. 2019. "Obstetri Williams, Vol. 2." EGC.

Darmareja, Rycco, Riama Marlyn Sihombing, Mukhoirotin Mukhoirotin, Masta Haro, Tesha Hestyana Sari, Jeanny Rantung, Imanuel Sri Mei Wulandari, Tri Suwarto, and Adventina Delima Hutapea. 2021. Dasar-Dasar Keperawatan: Konsep Untuk Mahasiswa Keperawatan. Yayasan Kita Menulis.

Diasih, Yuhani. 2017. "Faktor-Faktor Yang Berhubungan Dengan Upaya Wanita Usia Subur Melakukan Deteksi Dini Kanker Serviks." 122-32.

Dinas Kesehatan Provinsi Sumatera utara. 2018. Profil Kesehatan Provinsi Sumatera Utara Tahun 2018.

Dinkes Sumut, 2019. 2019. Profil Kesehatan Provinsi Sumatera Utara Tahun 2018. Vol. 53.

Husnah, Syahdah Iksiroh Al. 2021. "Studi Literatur Perbedaan Pemeriksaan IVA Dan Pap Smear Dalam Mencegah Kanker Serviks Melalui Review Jurnal Tahun 2016-2021."

Ikrima, Mila. 2015. "Pengaruh Pendidikan Kesehatan Deteksi Dini Kanker Serviks Dengan Metode IVA Terhadap Motivasi Ibu Di Kelurahan Mojosongo RW XIV Surakarta." Jurnal Penelitian 1-10.

Indonesia, Kementerian Kesehatan Republik. 2017. "Data Dan Informasi Profil Kesehatan Indonesia 2016." Jakarta: Pusat Data Dan Informasi Kementerian Kesehatan RI. 
Kemenkes, R. I. 2017. "Data Dan Informasi Profil Kesehatan Indonesia." Jakarta: Kemenkes RI.

Mardiah, Mardiah. 2019. "Studi Literatur Predisposisi Dan Upaya Prevensi Keganasan Kanker Serviks Pada Wanita." Pp. 167-76 in Proceeding of Sari Mulia University Midwifery National Seminars. Vol. 1.

Marhaeni A, Gusti. 2016. "Keputihan Pada Wanita." Jurnal Skala Husada.

Mayanda, Vinta. 2019. "Hubungan Karakteristik Wanita Dengan Kejadian Kanker Serviks Di Rumah Sakit Umum Mutia Sari." Jurnal Bidan Komunitas 2(1):47-56.

Mitchell, Richard N. 2019. "Buku Saku Dasar Patologis Penyakit." EGC.

Mochtar, Rustam. 2019. "Sinopsis Obstetri, Jilid 2." EGC.

Notoadmodjo. 2016. Pengantar IImu Perilaku Kesehatan.

Nugroho, Taufan. 2019. "OBSGYN: Obstetri Dan Ginekologi Untuk Kebidanan Dan Keperawatan."

Nur, Akbar, and S. Kep. 2017. Buku Saku Keperawatan Dan Kebidanan. Vol. 1. CELEBES MEDIA PERKASA.

Pieter, Herri Zan. 2018. Pengantar Psikologi Untuk Kebidanan. Kencana.

Putri, Pratiwi Syah. 2018. "Faktor-Faktor Yang Berhubungan Dengan Pencegahan Keputihan (Flour Albus) Pada Remaja Madya Di SMA AI Ulum Medan." Thesis.

Rayburn, William F., and J.Christopher Carey. 2019. "Obstetri \& Ginekologi."
Safitri, Faradilla, and Nuzulul Rahmi. 2019. "Determinan Kejadian Kanker Serviks Di Rumah Sakit Umum Daerah Dr. Zainoel Abidin, Provinsi Aceh." Media Penelitian Dan Pengembangan Kesehatan 29(1):89-98.

Sastrawinata, Sulaiman, D. Martaadisoebrata, and F. Wirakusumah. 2017. "Obstetri Patologi IImu Kesehatan Reproduksi." Edisi.

Sayuti, Muhammad, and Nouva Nouva. 2019. "KANKER KOLOREKTAL." AVERROUS: Jurnal Kedokteran Dan Kesehatan Malikussaleh 5(2):76-88.

Utami, Nungky Marcelia. 2013. "Hubungan Tingkat Pengetahuan Pasangan Usia Subur Dengan Perilaku Deteksi Dini Kanker Serviks Di Wilayah Kerja Puskesmas Sangkrah Kecamatan Pasar Kliwon Surakarta." Naskah Publikasi 1-16.

WHO. 2019. "Maternal Mortality." WHO.

Wigati, Atun, and Ana Zumrotun Nisak. 2017. "Peran Dukungan Keluarga Terhadap Pengambilan Keputusan Deteksi Dini Kanker Serviks." Indonesia Jurnal Kebidanan 1(1):12-17.

Wijayanti, Indah. 2015. "Hubungan Dukungan Suami Dengan Keikutsertaan IVA Pada Wanita Usia Subur Di Puskesmas Sedayu I Dan Puskesmas Sedayu II." Naskah Publikasi 1-13.

Yuliwati. 2012. Faktor-Faktor Yang Berhubungan Dengan Perilaku WUS Dalam Deteksi Dini Kanker Leher Rahim Metode IVA Di Wilayah Puskesmas Prembun Kabupaten Kebumen. Jakarta: Fakultas Kesehatan Masyrakat Univaersitas Indonesia. 